\title{
Evaluation and modeling of synergy to pheromone and plant kairomone in American palm weevil
}

\author{
Imen Saïd ${ }^{1}$, Belhassen Kaabi ${ }^{2^{*}}$ and Didier Rochat ${ }^{3}$
}

\begin{abstract}
Background: Many behavioral responses to odors are synergistic, particularly in insects. In beetles, synergy often involves a pheromone and a plant odor, and pest management relies on them for the use of combined lures. To investigate olfactory synergy mechanisms, we need to distinguish synergistic effects from additive ones, when all components of the mixture are active.

Results: As versatile tools and procedures were not available, we developed a bioassay, and a mathematical model to evaluate synergy between aggregation pheromone $(P)$ and host plant odors (kairomone: $K$ ) in the American palm weevil, a pest insect showing enhanced responses to $\mathrm{P}+\mathrm{K}$ mixtures. Responses to synthetic $\mathrm{P}$ and natural $\mathrm{K}$ were obtained using a 4-arm olfactometer coupled to a controlled volatile delivery system. We showed that: (1) Response thresholds were ca. 10 and $100 \mathrm{pg} / \mathrm{s}$ respectively for $\mathrm{P}$ and $\mathrm{K}$. (2) Both stimuli induced similar maximum response. (3) Increasing the dose decreased the response for $P$ to the point of repellence and maintained a maximum response for $K$. (4) $P$ and $K$ were synergistic over a 100-fold range of doses with experimental responses to $\mathrm{P}+\mathrm{K}$ mixtures greater than the ones predicted assuming additive effects. Responses close to maximum were associated with the mixture amounts below the response threshold for both $\mathrm{P}$ and $\mathrm{K}$.

Conclusion: These results confirm the role of olfactory synergy in optimizing active host-plant localization by phytophagous insects. Our evaluation procedure can be generalized to test synergistic or inhibitory integrated responses of various odor mixtures for various insects.
\end{abstract}

\section{Background}

In chemosensory perception, synergy is a famous case of mixture interaction. The mixture acts as a whole whose property differs from those of its components [1-5]. Synergy is considered also an evolutionary adaptation that makes relationships between organisms more specific and/or cost-effective [6-9]. Semiochemicals act commonly in synergy on the behavior of phytophagous insects and many reports concern aggregation pheromone and plant volatiles, mainly in Coleoptera [6]. Such behavioral synergy is well exemplified in Rhynchophorinae weevils whose responses to aggregation pheromones are dramatically increased by the perception of the host plant odors as shown by the comparative captures by

\footnotetext{
* Correspondence: belhassen.kaabi@pasteur.rns.tn

${ }^{2}$ Laboratory of Epidemiology and Ecology of Parasites, Institut Pasteur de

Tunis, Tunis-Belvedère, 1002, Tunisia

Full list of author information is available at the end of the article
}

odor-baited traps in the field [6,10-13]. For instance for Rhynchophorus palmarum, the American palm weevil, when the level of capture to pheromone only (either from living males or synthetic) is normalized to 1 , the captures to the plant odor ranged from 2.9 to 6.0 (oil palm stem or sugarcane stalk), while the combinations caught from 20.4 to 31.4 [14-16]. Based on these field evidences, the use of synthetic aggregation pheromones combined with various sources of plant volatiles have been extensively and successfully developed for mass trapping to monitor or control populations of pest palm weevils (Rhynchophorus spp.) [11,14,17-28]. For an optimal trapping yield, it is necessary to use and renew the natural plant pieces, to maintain synergy with the pheromones, all more important as the pheromones are weakly active alone [14,29-35]. Despite various attempts, the plant synergistic odorous principle with the pheromones has not been fully characterized yet. Adding 
ethyl-acetate (EtOAc), one of the main constituent of the odors from the raw plant baits, proved to enhance the responses to the pheromone alone or when combined to a natural plant material for various Rhynchophorinae species $[16,27,34,36]$. The additional volatiles were reported to improve synergy by EtOAc only with Rhynchophorus palmarum pheromone, and to be competitive with a natural plant odor [17,27], but did not confirm a versatile and reproducible activity (Rochat, unpublished; Oehlschlager, personal communication), thus raising the issue of the methodology used to achieve the comparisons of the odor mixtures and their properties.

A central issue to improving semiochemical-based trapping against pest insects is to understand the sensory mechanisms involved, especially when mixture interaction dramatically changes the behavioral responses. The question is whether, a higher response to a combination of pheromone and plant odor is quantitatively truly synergistic, or possibly the results of the superimposition of different effects. Compounds $A$ and $B$ are synergistic when the effect of $A+B$ is higher than the sum of individual activities of $\mathrm{A}$ and $\mathrm{B}$. To be rigorous this notion must be quantified: thus $A$ and $B$ are synergistic if and only if $\mathrm{R}_{\mathrm{A}+\mathrm{B}}(\mathrm{d})>\mathrm{R}_{\mathrm{A}}(p, \mathrm{~d})+\mathrm{R}_{\mathrm{B}}\left(p^{\prime}, \mathrm{d}\right)$ where $\mathrm{R}_{\mathrm{X}}$ is the response to $\mathrm{X} \in\{A, B, A+B\}, \mathrm{d}$ is the dose of $\mathrm{A}+\mathrm{B}$ mixture, $p$ is the percent of $\mathrm{A}$, and $p$ ' the complement $(1-p)$ of $\mathrm{B}$. When $\mathrm{A}$ or $\mathrm{B}$ is inactive, synergy is easily established. On the contrary, when both components are active, validating synergy requires comparing experimental and predicted activities of $\mathrm{A}+\mathrm{B}$ under the hypothesis of additive effects. Calculation of the additive response is critical, as dose/response (D/R) relationships are essentially nonlinear. Rigorous validation of synergy often has been ignored or based only on limited quantitative data for behavioral responses or evaluated in reference to simple co-activity or synergistic indices e.g. [37], which leads to some confusion or controversy as pointed by Alonso-Amelot and Calcagno [1].

Dose normalization and $D / R$ relationships to plant kairomones are lacking in the literature for Rhynchophorus weevils and specifically for $R$. palmarum where most pragmatic field trials have been carried-out using various plant materials that emitted undetermined amounts of odors [14,15,27,30,32,35,38].

To quantify synergy between aggregation pheromone and a plant odor in the American palm weevil, Rhynchophorus palmarum, we developed an olfactometer procedure and a new modeling approach. The work focused on the response by insect walk to $30 \mathrm{~cm}$ distant sources, a step, which is occurring in natural conditions. Responses to synthetic aggregation pheromone (P), to natural odor of fermented sugar cane $(\mathrm{K})$, and to the mixture $(\mathrm{P}+\mathrm{K})$ were measured independently. The $\mathrm{D} / \mathrm{R}$ curve to each component was fitted to functions that served in turn to calculate the predicted additive response to $\mathrm{P}+\mathrm{K}$. As an alternative quick approach, relative responses to $\mathrm{P}, \mathrm{K}$, and $\mathrm{P}+\mathrm{K}$ were also evaluated in choice situations in the same device for comparison. Results are discussed from both methodological and biological points of view regarding olfactory synergistic responses in insects and the olfactory behavior of palm weevils in particular.

\section{Materials and methods \\ Insects}

The palm weevils, $R$. palmarum, came from Colombia and French Guyana. We used field-collected insects, caught in traps baited with synthetic pheromone + sugar cane, and brought to France. Males and females were kept separately under tropical conditions $\left(23-28^{\circ} \mathrm{C}\right.$; R.H.: 75-90\%; L13:D11) on sugar cane. Ten to 15 days conditioning to the new environment (laboratory conditions) were necessary to eliminate any physiological disturbance due to the time lag. The day before experimentations, insects were isolated in small boxes without food. They were transferred to a bioassay room, and allowed to acclimate for at least $30 \mathrm{~min}$, before testing.

\section{Laboratory Set-up}

We used a modified 4-arm olfactometer (Laucoin S.A., Thoiry, France) following the model described by Vet et al. [39], coupled to an adaptation of Bartelt and Zilkowsky's volatile delivery system [40]. A detailed description of the whole device, calibration, and evaluation was reported in Saïd et al. [41].

\section{Chemicals}

We used synthetic aggregation pheromone (rhynchophorol) and natural kairomone (the odor from fermented sugar cane juice). Rhynchophorol (2-methyl-(5E)hepten-4-ol) [42] was synthesized by E.G.N.O.-Chimie (Tancarville, France), and has higher than $98 \%$ purity (gas chromatography: GC). The kairomone was prepared in the laboratory. A fresh sugar cane stalk was chopped into small pieces, and kept in an open glass vial under tropical conditions. Seven days later, these sugar cane pieces were pressed and their juice was kept in $4 \mathrm{ml}$ airtight vials at $-30^{\circ} \mathrm{C}$. Odor sources were $250 \mathrm{ml}$ silanized glass flasks filled with $100 \mathrm{ml}$ aqueous solutions of synthetic pheromone or sugar cane juice.

\section{Olfactometer Tests}

Eighteen to 22 weevils were tested in each experiment. Since previous reports $[15,27,34,41,42]$ showed that males and females respond similarly to both the aggregation pheromone and the host plant odors, weevils' sex 
was not considered an experimental factor. Nevertheless, and unless otherwise stated, similar numbers of males and females were used in all experiments.

Weevils were placed separately in the olfactometer centre. They were removed if they had not entered one arm within 5 min. The walking behavior was monitored during 10 min after an insect had first entered an arm. The following parameters were recorded: first choice (first arm entered), and residence time in each arm. Tests were run between the first and fourth hours of the night at $25 \pm 1^{\circ} \mathrm{C}$ Two configurations were evaluated: either with or without an odor choice (simple versus choice configuration).

\section{Simple configuration}

This was used to establish separately the $\mathrm{D} / \mathrm{R}$ curves to pheromone $(\mathrm{P})$, and to sugar cane odor $(\mathrm{K})$, and to calculate the predicted additive response to the mixture. Experimental responses to various $\mathrm{P}+\mathrm{K}$ mixtures were recorded in the same configuration for comparison with the calculated additive responses. One arm was odorized, by either synthetic pheromone, sugar cane odor, or the mixture, while the 3 remaining others were blank.

Seven doses of pheromone were evaluated using four aqueous solutions. Three solutions with six flow rates: $30 \mathrm{ng} / \mathrm{s}(100 \mu \mathrm{g} / \mathrm{ml})$ to $3 \times 10^{-4} \mathrm{ng} / \mathrm{s}$ (decadic steps) using either $10 \%$ or $100 \%$ of the source flow rate and the fourth at $60 \mathrm{ng} / \mathrm{s}$. Aqueous solutions of sugar cane juice were prepared by successive dilutions by 10 . Solid phase micro-extration (SPME) was used to determine the concentration of fermented odors in gaseous phase from the source, as described in Said et al. [41]. SPME samples were analyzed with a Varian Star 3400 Cx gas chromatograph equipped with a flame ionization detector (FID) and a WCOT CPSil8-CB column $(25 \mathrm{~m} \times$ $0.32 \mathrm{~mm}$ (ID) $\times 0.4 \mu \mathrm{m}$ d.f.). The column was operated from $50^{\circ} \mathrm{C}$ (for $1 \mathrm{~min}$ ) to $70^{\circ} \mathrm{C}$ at $20^{\circ} \mathrm{C} / \mathrm{min}$ (plateau for $5 \mathrm{~min}$ ), then finally to $250^{\circ} \mathrm{C}$ (maintained for $3.5 \mathrm{~min}$ ) at $8^{\circ} \mathrm{C} / \mathrm{min}$. The injector and detector were heated at 230 and $260^{\circ} \mathrm{C}$, respectively.

Chromatographic analysis of volatiles emitted by fermented sugar cane juice indicated that EtOAc accounted for about $90 \%$ of the total amount. Thus, doses of K were expressed as the dose of EtOAc emitted from the solutions. Seven flow rates: $3 \times 10^{3}$ (pure juice) to 3.3 $\times 10^{-3} \mathrm{ng} / \mathrm{s}$ (decadic steps) of EtOAc were tested from four aqueous dilutions. Nine $\mathrm{P}+\mathrm{K}$ mixtures were tested at three total flow rates $\left(3 \times 10^{-1}, 3 \times 10^{-2}\right.$, and $3 \times 10^{-3} \mathrm{ng} /$ s), with $25 \%, 50 \%$, and $75 \%$ of $\mathrm{P}$ for each dose. Kairomone dose was based on the amount of EtOAc.

\section{Choice configuration}

This was evaluated at one $\mathrm{P}+\mathrm{K}$ dose to examine whether it could serve as a rapid bioassay to indicate the insect's preference for the mixture over individual components. We analyzed the responses of $R$. palmarum exposed simultaneously to: i)- a $3 \times 10^{-3} \mathrm{ng} / \mathrm{s}$ delivery rate of $\mathrm{P}$; ii) - a $0.33 \mathrm{ng} / \mathrm{s}$ delivery of $\mathrm{K}$ (dose based on EtOAc content); iii)- the $\mathrm{P}+\mathrm{K}$ mixture delivery rate $\left(3 \times 10^{-3}\right.$ and $0.33 \mathrm{ng} / \mathrm{s}$ ); and iv)- odorless air (control). These trials were made initially, prior to establishing the dose response curve to pheromone and plant odors, and therefore they did not necessarily fit the response thresholds. Responses were recorded for all three possible relative positions of $\mathrm{P}, \mathrm{K}$ and $\mathrm{P}+\mathrm{K}$ (i, ii and iii) with $\mathrm{P}+\mathrm{K}$ opposite to $\mathrm{P}, \mathrm{K}$ or control) and analyzed separately for each configuration. Two odor sources (P and $\mathrm{K})$ were used. The flow outlet from each source flask was divided into two branches, one going to an olfactometer input and the other to the mixing zone of the semiochemical delivery system, so that a mixture of $\mathrm{P}+\mathrm{K}$ could be directed to a third input of the olfactometer. The fourth olfactometer input received odorless air (control).

\section{Statistical Analysis}

Two variables quantified the insect behavior: (a)- first choice i.e. the arm entered at the beginning of the test, and (b)- residence time in each arm. Numbers of first choices were recorded to evaluate insect's ability to discriminate odors at the beginning of the experiment and this was analyzed by the multinomial test with the null hypothesis $H_{0}$ is equal probability to choose arm [43]. Mean residence times in each arm were compared using one-way ANOVA on $(x+0.5)^{1 / 2}$ transformed data (to insure normality) with arms as blocks, this was followed by Dunnett test for simple configuration (pheromone versus every other arm) or by Newman-Keul test (to avoid multiple comparisons) for choice configuration [44]. All the analysis was done using $\alpha=0.05$ as significance level.

\section{Synergy Evaluation}

The isobologram $[45,46]$ is a powerful graphical tool that is commonly used for analyzing the joint response of a simple chemical mixture. However, this approach does not provide a statistical distinction between simple additive effect and synergy. Other popular methods for testing synergy in pharmacology were described in [47]; however, they are based on fixed potency (attractiveness in this case) ratio of the chemical components used and suppose a semi-linear dose-effect relationship of the mixture components, which is rarely the case. In this study, we provided and used a new alternative method described below that surmounts the aforementioned difficulties.

\section{Mathematical Modeling}

We choose models that fitted best $D / R$ experimental data for $\mathrm{P}$ and $\mathrm{K}$ among classical (polynomial and 
exponential) functions used in biology. Parameters were fitted using the least square criterion within the experimental range of 0.003 to $30 \mathrm{ng} / \mathrm{s}$ odor doses. Regression coefficients $\left(\mathrm{r}^{2}\right)$ and fitting quality were assessed using the F-test. Responses to odor X (either P or K), $\mathrm{R}_{\mathrm{X}}$, varied from a minimum, $m_{X}$, to a maximum, $M_{X}$, because of the olfactometer properties. We defined $\mathrm{R}_{\mathrm{ad}}(\mathrm{D}, p)$ to be the predicted response of $\mathrm{P}+\mathrm{K}$ mixture at a dose $\mathrm{D}$ (0.003-60 ng/s) with $p$ the percentage of $\mathrm{P}(0-100 \%)$, and $p^{\prime}=1-p$ percentage of $\mathrm{K}$ assuming additive effect of $\mathrm{P}$ and $\mathrm{K}$. This was calculated by equation $\mathrm{E}-1$ from the modeled responses $R_{\mathrm{P}}$ and $\mathrm{R}_{\mathrm{K}}$ :

$$
R_{a d}(D, p)=m+(M-m) \cdot\left[a p \cdot p \cdot \frac{R_{P}(p \cdot D)-m_{P}}{M_{P}-m_{P}}+a_{K} \cdot p^{\prime} \cdot \frac{R_{K}\left(p^{\prime} \cdot D\right)-m_{K}}{M_{K}-m_{K}}\right] .
$$

Where $\mathrm{a}_{\mathrm{X}}$ are correction factors for odor $\mathrm{X}$ (either $\mathrm{P}$ or $K$ ), which compensate for the difference between $M_{K}$ and $\mathrm{M}_{\mathrm{P}}$, and the non-linear $\mathrm{D} / \mathrm{R}$ relationships (first and second members of the product in equation E-2, respectively). Values for these coefficients were estimated using equation E-2 assuming homogenous mixing.

$$
a_{X}=\left(\frac{M_{X}-m_{X}}{M-m}\right)\left(\frac{R_{X}(D)-m}{p R_{X}(p D)+p^{\prime} R_{X}\left(p^{\prime} D\right)-m}\right) .
$$

The Minimum ( $\mathrm{m}$ ) and the maximum (M) responses to the mixture were set to $145 \mathrm{~s}$ (value under random movements) and the greatest of the maxima $M_{K}$ and $M_{P}$, respectively. All calculations were made using Matlab and Excel $[48,49]$. Finally, we compared the modeled additive responses $R_{a d}$ to the experimental responses $\left(R_{e x}\right)$ for each $P+K$ mixture using Student t-tests (with $H_{0}: \mathrm{R}_{\mathrm{ex}}=\mathrm{R}_{\mathrm{ad}}$ ).

\section{Results}

\section{Responses to Odors}

Choice configurations - In all three relative positions of the stimuli, all weevils had left the central zone within 5 min. Most of their activities occurred in the $\mathrm{P}+\mathrm{K}$ arm.
Weevils that had left this arm for another one, tended to move around for a while, and then returned to the mixture arm. Generally, they moved along the olfactometer edges or the (virtual) boundaries between arms. The relative positions of the stimuli in the olfactometer induced differences in responses (Table 1). The highest response rate to $\mathrm{P}+\mathrm{K}$ was recorded when $\mathrm{P}$ and $\mathrm{K}$ sources were both adjacent to $\mathrm{P}+\mathrm{K}$ source, rather than opposite to the control source. In which case; $65 \%$ of weevils choose $\mathrm{P}+\mathrm{K}$ first $(p$-value $<0.001)$, which was also visited significantly longer ( $47 \pm 6 \%$ test duration) than any other field (about 3-fold; Newman-Keuls test, $p$-value $<0.05)$. When the control source was adjacent to the $\mathrm{P}+\mathrm{K}$ source, the time spent in the mixture was greater than that spent in the control and the opposite fields, regardless of the treatment. However, the staying time did not differ significantly from those spent in the other adjacent fields, odorized with either $\mathrm{K}$ or P. First choice for $\mathrm{P}+\mathrm{K}$ was significant only when $\mathrm{P}+\mathrm{K}$ were opposite to $\mathrm{P}$ in the olfactometer $(p$-value $<0.05$; multinomial test).

\section{Simple configuration}

First choices for odorized field were associated to residence time (Dunnett test, $p$-value $<0.05$ ) for both $\mathrm{P}$ and $\mathrm{K}$ over the ranges of doses evaluated (Figures $1 \mathrm{a}$ versus $1 \mathrm{~b}$ and $1 \mathrm{c})$.

\section{Pheromone}

Weevils entered more often the odorized arm from $3 \times$ $10^{-2}$ to $30 \mathrm{ng} / \mathrm{s}$ of P but not for $3 \times 10^{-4}, 3 \times 10^{-3}$ and $60 \mathrm{ng} / \mathrm{s}$ delivery rates (Figures $1 \mathrm{a}$ and $1 \mathrm{~b}$ ). The time spent in the P field increased with delivery rates, from $3 \times 10^{-3}$ to $0.3 \mathrm{ng} / \mathrm{s}$, and then decreased with further increases of delivery rates. It peaked at $56 \pm 4 \%$ test duration for $0.3 \mathrm{ng} / \mathrm{s}$ (180 ng/10 min) delivery rate. At $60 \mathrm{ng} / \mathrm{s}$, weevils avoided P odorized field (118 s; with $H_{0}$ : average staying time $=145 \mathrm{~s} ;$ p-value $<0.05$; Figure 1a).

Table 1 Responses of American palm weevils ( $n=9$ males +9 females) simultaneously exposed to synthetic aggregation pheromone ( $\mathrm{P}: 3 \times 10^{-3} \mathrm{ng} / \mathrm{s}$ ), natural odor of fermented sugar cane (K: including $90 \%$ ethyl acetate delivered at $\mathbf{0 . 3 3} \mathrm{ng} / \mathrm{s})$, mixture of both $(P+K)$, and odorless air (control) in a 4-arm olfactometer, according to the

\begin{tabular}{|c|c|c|c|c|c|}
\hline \multirow[t]{2}{*}{ Response criterion (\%) } & \multirow[t]{2}{*}{ Relative position of stimuli: $\mathrm{P}=\mathrm{K}$ opposite } & \multicolumn{4}{|c|}{ Stimulus in olfactometer arm } \\
\hline & & Control & K & $\mathbf{P}$ & $\mathrm{P}+\mathrm{K}$ \\
\hline \multirow[t]{3}{*}{ First choice: arm entered first ${ }^{1}$} & $P$ & 0 & 22 & 22 & $56^{* *}$ \\
\hline & K & 6 & 33 & 28 & 33 \\
\hline & Control & 0 & 29 & 6 & $65^{* * *}$ \\
\hline \multirow[t]{3}{*}{ Mean time in arm after $10 \mathrm{~min}^{2}$} & $P$ & $21^{\mathrm{b}}$ & $21^{\mathrm{ab}}$ & $15^{\mathrm{b}}$ & $43^{\mathrm{a}}$ \\
\hline & K & $14^{\mathrm{b}}$ & $17^{\mathrm{b}}$ & $29^{\mathrm{ab}}$ & $40^{\mathrm{a}}$ \\
\hline & Control & $15^{\mathrm{b}}$ & $19^{\mathrm{b}}$ & $19^{\mathrm{b}}$ & $47^{\mathrm{a}}$ \\
\hline
\end{tabular}
relative positions of the odors delivered at constant flow rates from aqueous solutions

${ }^{1}$ Significantly differs from random with: ${ }^{* *}: p$-value $<0.01{ }^{* * *}: p$-value $<0.001$ (Binomial Tests).

${ }^{2}$ Mean times in arm, at a given relative position, with same letter do not differ significantly (Newman-Keuls' tests; $p$-value $<0.05$ ). 


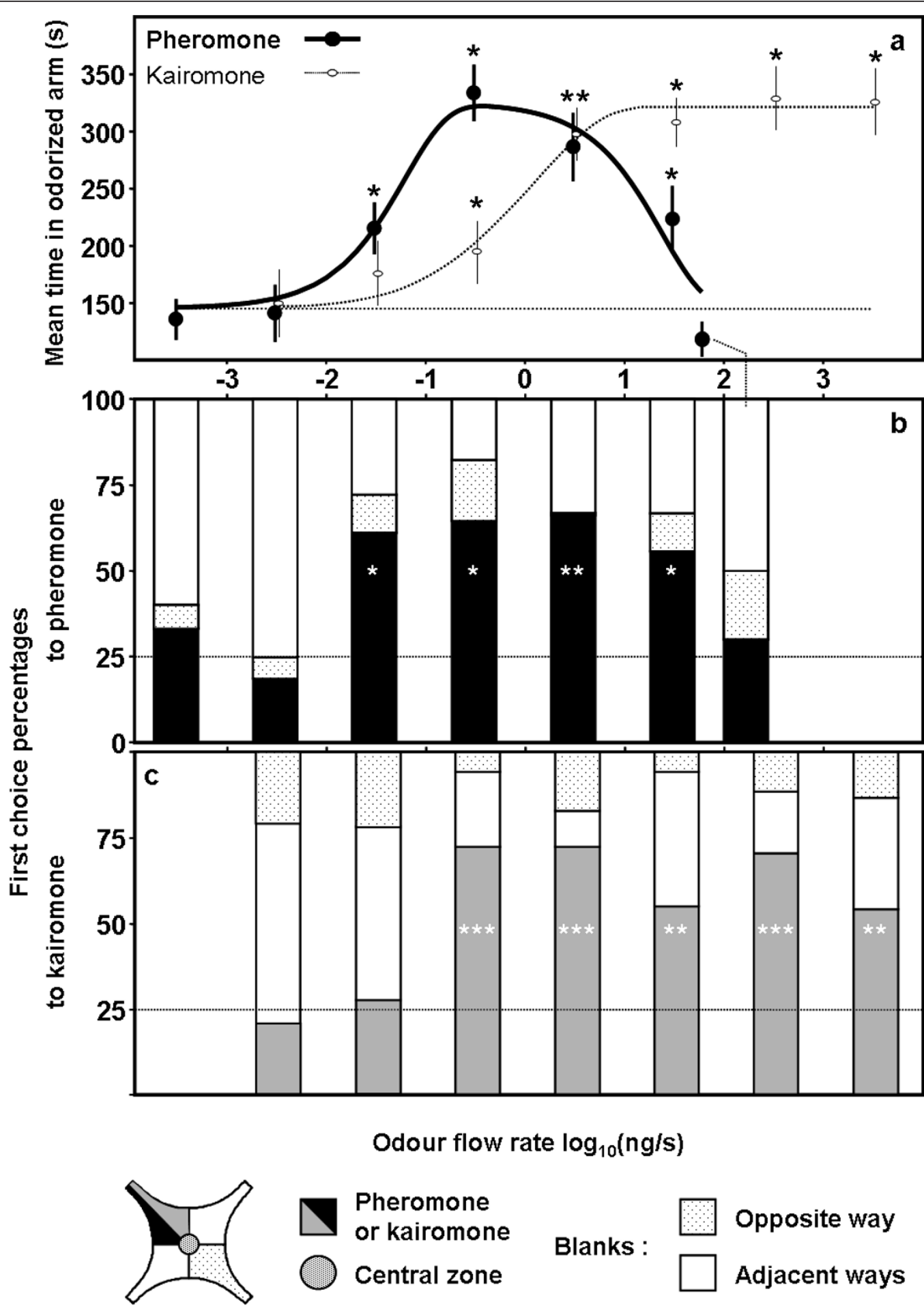

Figure 1 Responses of American palm weevils ( $n=20 \pm 2$ males + females) in a 4-arm olfactometer to seven doses of synthetic aggregation pheromone (2-methyl-(5E)-hepten-4-ol) and seven doses of fermented sugar cane odor (kairomone) delivered at

constant flow rates by the volatile delivery system. a - Mean ( \pm standard error) time spent in pheromone (plain large circles) or kairomone (thin open circles) arm during a 10 min test (*: different from control arms; Dunnett test, $p$-value < 0.05; straight line at $145 \mathrm{~s}$ : residence time in one arm in the absence of effect). Modeled responses to pheromone $\left(R_{p}\right)$ and to kairomone $\left(R_{k}\right)$ shown as a bold line and a thin dotted line, respectively. Arms entered first (first choices): $\mathrm{b}$ - with pheromone and $\mathrm{c}$ - with kairomone; significant with: *: $p$-value $<0.05 ;{ }^{*}: p$-value $<0.01$ and **: $p$-value $<0.001$ (binomial tests). Doted line at 25\%: random choice. 


\section{Kairomone}

Insects responded significantly to sugar cane odor for delivery rates between 0.33 and $3300 \mathrm{ng} / \mathrm{s}$ EtOAc but not for 2 lower doses (minimum $3.3 \times 10^{-3} \mathrm{ng} / \mathrm{s}$ EtOAc; Figure $1 \mathrm{a}$ and $1 \mathrm{c}$ ). Residence time reached similar plateau to the one observed with $\mathrm{P}$, but for higher delivery rates, and the maximum was maintained from 3.3 to $3300 \mathrm{ng} / \mathrm{s}$ EtOAc. The plateau for the two D/R curves did not reflect an artifact limit because higher residence times were recorded for at least two mixtures (Figure 2 and unpublished data). Maximum time spent in odorized field was recorded at $330 \mathrm{ng} / \mathrm{s}$ EtOAc delivery rate (55 $\pm 5 \%$ duration time).

\section{Modeling Responses to $\mathrm{P}$ and $\mathrm{K}$}

The responses, residence time (in seconds) in the odorized arm were expressed as functions of the delivery rate of odor (in $\mathrm{ng} / \mathrm{s}$ ). The response to $X \in\{P, K, P+K\}$ can be modeled using various regression functions [50]. Parameters of the models included the bounds for the response $\left(m_{X}\right.$ and $\left.M_{X}\right)$, and assumptions made about them determined the bound values calculated for the mixture ( $\mathrm{m}$ and $\mathrm{M}$ ). We therefore evaluated several regression models for $\mathrm{m}_{\mathrm{X}}$ and $\mathrm{M}_{\mathrm{X}}$. All of them led to significant correlations ( $\mathrm{r}^{2}$ from 0.37 to 0.43 , p-value < 0.0001 ), and extreme values for $m_{X} ; M_{X}$ and $M_{X}-m_{X}$ differed by less than $15 \mathrm{~s}$. This was considered negligible as compared to the amplitude of the response, which ranged from 145 to $320 \mathrm{~s}$ on average. The response to $\mathrm{K}$ was best fitted by the function described in equation E3 with parameters $m_{K}, M_{K}$, a, and b:

$$
R_{K}(D)=M_{K} \times\left(1+\left[\left(\frac{m_{K}}{M_{K}}\right)^{1 / a}-1\right] \times e^{-D}\right)^{b} .
$$

The response to $\mathrm{P}$ was best fitted by a sum of two exponentials (equation E-4) and parameters $m_{P}, M_{P}, c$ and $d: R_{P}(D)=M_{P} \times e^{c D}+\left(M_{P}-m_{P}\right) \times e^{d D}(E-4)$ Values of these parameters and the fitting quality are given in Table 2. The corresponding curves, $R_{P}$ and $R_{K}$, are shown in Figure 1a. Further calculations to build the additive response to $\mathrm{P}+\mathrm{K}\left(\mathrm{R}_{\mathrm{ad}}\right)$ were performed using $\mathrm{E}$ 1 and E-2.

\section{Experimental Responses to $\mathrm{P}+\mathrm{K}$ Mixtures $\left(\mathrm{R}_{\mathrm{ex}}\right)$ : Comparison to Modeled Additive Response $\left(\mathbf{R}_{\mathrm{ad}}\right)$}

Differences in $R_{a d}$ according to the various scenarios applied to establish $\mathrm{D} / \mathrm{R}$ fittings to $\mathrm{P}$ and $\mathrm{K}$ were small in absolute values $(<20 \mathrm{~s})$ and negligible as compared to $R_{\mathrm{ex}}$. $\mathrm{R}_{\mathrm{ad}}$ appeared to be a complex surface: several mixtures of either different quantity (D) or quality (pheromone proportion $p$ ) gave the same level of response (Figure 3 ). However, $\mathrm{R}_{\mathrm{ad}}$ values for pheromone flow rates above $30 \mathrm{ng} / \mathrm{s}$ cannot be considered accurate, since the model used for $\mathrm{P}$ did not fully integrate the repellent effect of $\mathrm{P}$ at $60 \mathrm{ng} / \mathrm{s}$ (See discussion).

Insects spent longer time in the $\mathrm{P}+\mathrm{K}$ arm than in any control arm, whatever the mixture delivery rate and the $\mathrm{P}: \mathrm{K}$ ratio (Dunnett test, $p$-value $<0.05$ ). All experimental responses to mixtures were above the predicted additive responses (Figure 3). For 2 flow rates; 0.003 and $0.03 \mathrm{ng} / \mathrm{s}$, all experimental data $\left(R_{\mathrm{ex}}\right)$ were significantly greater than the modeled additive responses (One-sided student T-test, $p$-value $<0.05$; Figure 2 middle, and bottom). Responses to the lowest mixture delivery rate (3 $\mathrm{pg} / \mathrm{s}$ ) were particularly spectacular because both components were below or at the response threshold. At the highest delivery rate tested $(0.3 \mathrm{ng} / \mathrm{s}), R_{\mathrm{ex}}$ was also greater than the corresponding $\mathrm{R}_{\mathrm{ad}}$, for $25 \%$ and $50 \%$, but not for $75 \%$, of $\mathrm{P}$ in the mixture. For the latter mixture, $\mathrm{R}_{\mathrm{ex}}$ was similar to the response obtained for $\mathrm{P}$ alone, i.e. the maximum effect recorded to either $\mathrm{P}$ or $\mathrm{K}$ alone (Figure 2 at the top). Weevils showed the highest average response ever recorded to any stimulus in the olfactometer to date: 379 s, i.e. $63 \pm 3 \%$ of test duration, a value that is greater than the maximum responses recorded to $\mathrm{P}$ alone and to $\mathrm{K}$ alone (322 s). Synergy (expressed as $R_{e x} / R_{a d}$ ) is considerable at $0.003 \mathrm{ng} / \mathrm{s}$ : from 40 to 100 , medium at $0.03 \mathrm{ng} / \mathrm{s}$ : from 3 to 13 and weak at $0.3 \mathrm{ng} / \mathrm{s}$, and it is around 2 for the two synergistic ratios.

\section{Conclusion and Discussion}

Dealing with synergy of attractive semio-chemicals requires reliable records of animal locomotory responses under strict laboratory conditions. This is always a challenge. Precise control of the environment is facilitated by the small size of arthropods in general. However, some specific adaptations are always necessary [51,52]. Few investigations concerned with large flying insects are mainly made in large cages, rooms, or greenhouses [53-55]. We showed previously that an enlarged 4-arm olfactometer coupled to an odor delivery system was a useful alternative to large cages when measuring the responses of 4 to 8 - $\mathrm{cm}$ long palm beetles, including $R$. palmarum $[41,56]$. As a first step, this device allowed us on a quantitative basis to establish the high sensitivity of the palm weevil to semio-chemicals delivered at constant flow rates, hitherto roughly estimated from field trapping. Weevils showed a response threshold to pheromone around $10 \mathrm{pg} / \mathrm{s}$, and an optimum around $1 \mathrm{ng} / \mathrm{s}$. Pheromone was repellent at high doses, confirming what was reported by Jaffé et al. [34], except when the dose was much lower $(3.6 \mu \mathrm{g} / \mathrm{min}$ versus headspace from $3 \mathrm{ml}$ pure pheromone). However, this may be out of the natural physiological range because repellence was never observed in the field [14,35] and Rochat (unpublished data). High amount of pheromone may 


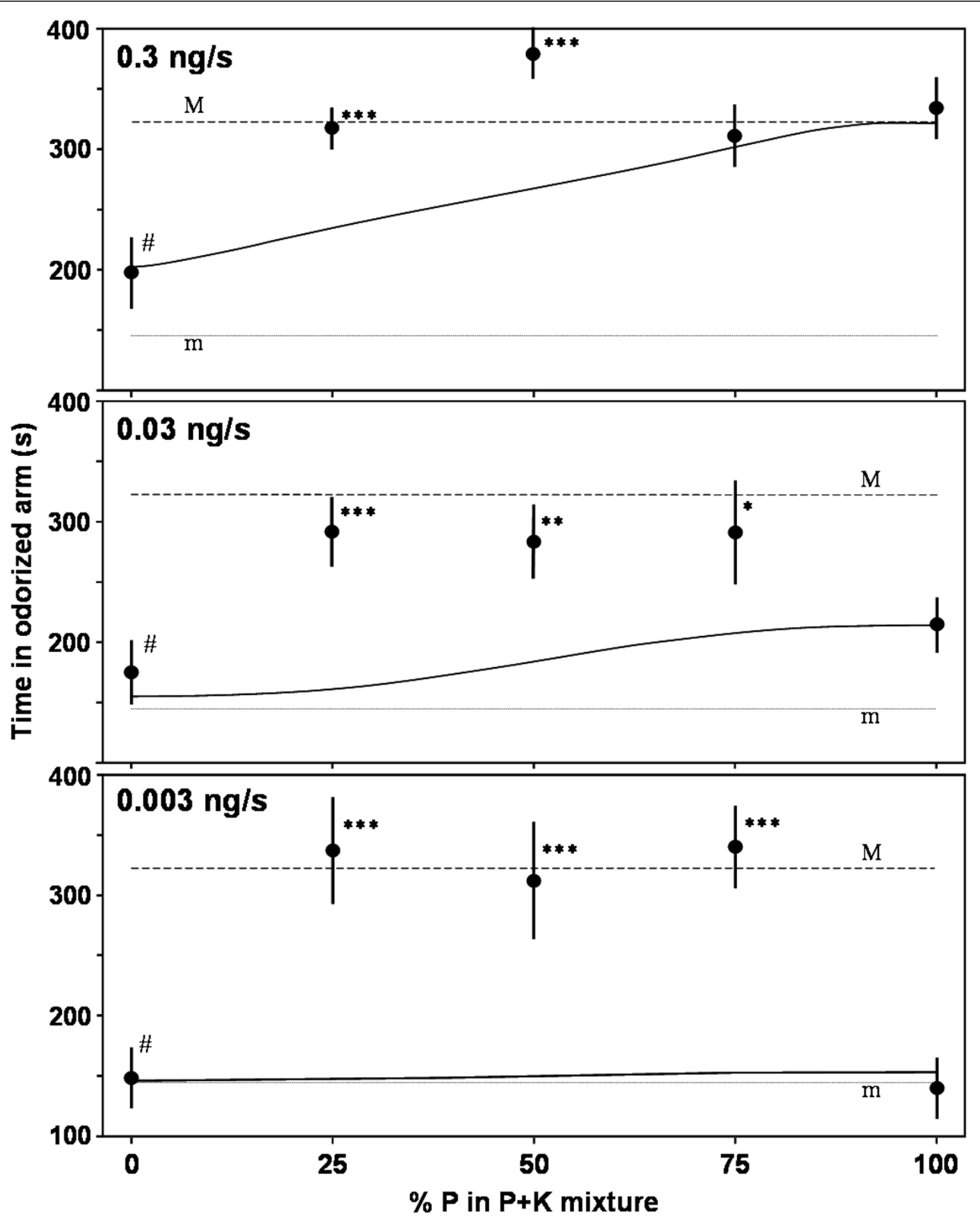

Figure 2 Compared experimental (black dots + bars: $m \pm$ s.e.) and modeled additive (bold lines) responses of American palm weevils to mixtures of synthetic aggregation pheromone $(\mathrm{P})$ and natural odor of fermented sugar cane $(\mathrm{K})$ in a 4-arm olfactometer for three flow rates $(0.3,0.03,0.003 \mathrm{ng} / \mathrm{s}$; \#: actual flow rates $s$ of $0.0033,0.033$ and $0.33 \mathrm{ng} / \mathrm{s}$ for pure $K)$ and five $P: K$ ratios (P: 0, 25, 50, 75, $100 \%)$. There is synergy (experimental significantly greater than predicted additive response) with: *: $p$-value $<0.05,{ }^{* *}: p$-value $<0.01$, or ${ }^{* * *}$ : $p$-value $<0.001$ (Student t-test). Straight lines at 322 and 145 s: minimum $(\mathrm{m})$ and maximum $(\mathrm{M})$ expected responses under the hypothesis of additive effects of $P$ and $K$ respectively. 


\begin{tabular}{|c|c|c|c|c|c|}
\hline \multirow{2}{*}{$\begin{array}{l}\text { Model main } \\
\text { Features }\end{array}$} & \multicolumn{5}{|c|}{ Odor stimulus } \\
\hline & & Kair & omone: $\left(R_{K}\right)$ & Phe & romone: $\left(\mathrm{R}_{\mathrm{P}}\right)$ \\
\hline Type & & Logi & istic (sigmoid) & Sum & of 2 exponentials \\
\hline Maximum ${ }^{1}$ & & & $322 \pm 26$ & $M_{K}$ & $319 \pm 32$ \\
\hline Minimum ${ }^{1}$ & & $\mathrm{mp}_{\mathrm{p}}$ & 145 (set) & $m_{k}$ & 145 (set) \\
\hline \multirow[t]{2}{*}{ Parameters $^{1}$} & & a & $1.386 \pm 1.008$ & c & $-0.01518 \pm 0.00515$ \\
\hline & & $b$ & $0.2449 \pm 0.4100$ & $d$ & $-16.87 \pm 13.40$ \\
\hline \multirow[t]{4}{*}{$\mathrm{Fit}^{2}$} & $r^{2}$ & & 0.38 & & 0.43 \\
\hline & $F$ & & 94.40 & & 85.39 \\
\hline & $d f$ & & 1,112 & & 1,108 \\
\hline & $p$-value & & $<0.0001$ & & $<0.0001$ \\
\hline
\end{tabular}

${ }^{1}$ Constants of the models ( $a, b, c, d$, minima: $m_{x}$ and maxima: $M_{x}$ ) are given as mean $\pm 95 \%$ confidence intervals.

${ }^{2}$ Fit parameters: $r^{2}$ and the $F$ test value with degrees of freedom $(d f)$ and associated probability ( $p$-value)

nevertheless repel insects arriving at densely occupied trees like in male bark beetles where anti-aggregation pheromones also play an important role in the regulation of the population density [12,57-59]. Response threshold to a natural kairomone was recently determined at ca $100 \mathrm{pg} / \mathrm{s}$ based on the amount of EtOAc. This relatively low value indicates why a few cubic centimeters of sugar cane and $0.1 \mathrm{ml}$ of fermented sap of oil palm were efficient lures in the field or in the wind tunnel [27].

Our data support a similarity of chemical relationship to host plant in $R$. palmarum, sap beetles (Nitidulidae) and generalist fruit flies (Drosophila spp.): adults were strongly attracted to fermenting plant materials and had very low behavioral response thresholds to ubiquitous fermentation odors. Integrated response in Drosophila spp. and $R$. palmarum is associated with adaptation of the peripheral sensory system, in which highly sensitive and specific olfactory receptor neurons (ORNs) tuned to EtOAc and acetoin were identified. ORN response thresholds by single sensillum recordings were about $1 \mathrm{ng}$ or lower [60-63]. In addition, beetles use male aggregation pheromones that are active at or below the nanogram in laboratory bioassay $[64,65]$, and synergistic with fermenting odors e.g. [37]. R. palmarum detects the pheromone via highly sensitive and specific ORNs [60]. EtOAc enhanced the responses to rhynchophorol, but did not appear to synergize it according to previous olfactometer assay [17]. Its role as a primary attractant remains unclear $[27,34]$. The attraction property to EtOAc, either intrinsic or blended with other fermentation volatiles, appears to be widespread among Rhynchophorinae: $M$. hemipterus [26,31], R. ferrugineus [36], $R$. cruentatus [30] and $R$. phoenicis [32], and most Nitidulidae species studied [37,40,66-68]. EtOAc is also attractive to Drosophila melanogaster flies, but there is no information about any interaction with the cuticular sex pheromone [63].

In a second step and based on the $D / R$ curves, we investigated potential interaction between aggregation pheromone and host plant odor. Testing one pheromone dose below the response threshold and one active kairomone dose far from the maximum causing effect, the four-choice configuration rapidly indicated a preference by the weevil for the mixture over the individual components using a relatively small number of insects. The procedure should then be retained for such purposes and advantages. Basically, it could not validate synergy because the response to one odor depends on the others, particularly because the animal could move freely from one odor to another within a very short period. This can be partly compensated for by running binary choices with the mixture versus one component and using doses of one or the two components below response thresholds [37]. However, this requires lengthy testing and can be highly restrictive. Furthermore, the positions of different stimuli can affect the response levels to the mixture as reported by Vet et al. [39] because the probabilities of passing from one arm to another (adjacent versus opposite) are not actually equal in a 4 -arm olfactometer. With the practical view of quickly evidencing a preference for the mixture, it is better to place both components on both sides of the mixture to achieve high sensitivity.

Finally, predicted responses to $\mathrm{P}+\mathrm{K}$ mixtures under the assumption of additive effects was modeled over a broad range of doses, and compared to experimental responses recorded in the same simple configuration. A relevant additive model relies on the pertinence of the functions describing $\mathrm{D} / \mathrm{R}$ relationships to mixture components. A logistic function fitted properly the ascending part of the $\mathrm{D} / \mathrm{R}$ curve of $\mathrm{P}$ (from 0.0003 to $0.3 \mathrm{ng} / \mathrm{s}$ ). For K, we preferred the sum of two exponentials because it covered the decreasing responses to high pheromone amounts. These functions provided a good tool to compute the additive response to $\mathrm{P}+\mathrm{K}$. We did not include the highest pheromone dose avoided by the insects because we considered it a potential experimental artifact in the context of attractiveness. The additive model constructed for $\mathrm{P}+\mathrm{K}$ mixture relies on the use of simple equations. The only difficulty concerned the estimation of the expected maximum mixture response. We choose this conservatively to be the maximum experimental response to each component alone. Though our model fits a specific case, it is built from a general 


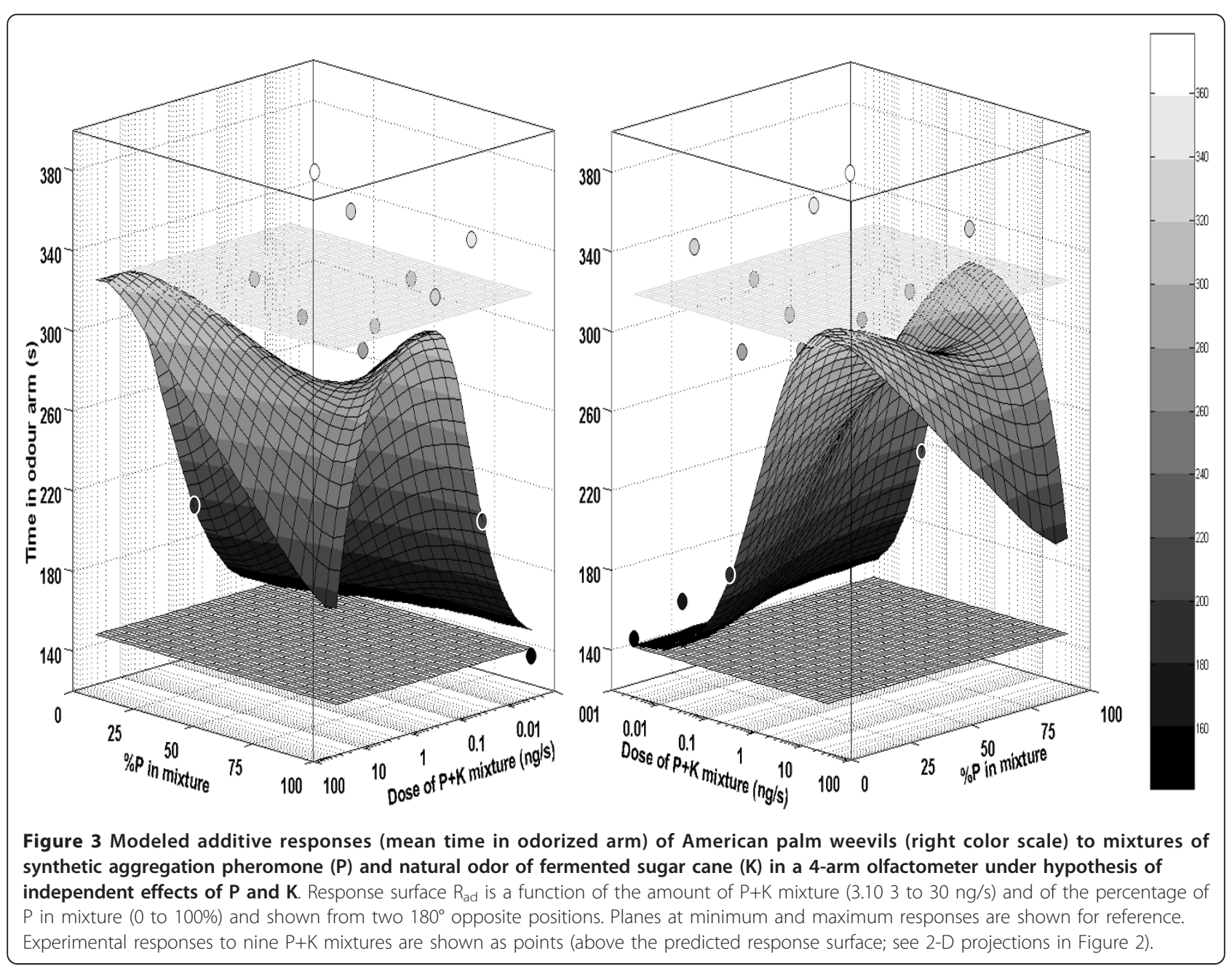

approach that can be applied to any case where the response is bounded and can be expressed as a percentage of the maximum. The model can also be applied to many odorants. On the other hand, efforts to model sensory interactions of odors or tastes in humans have been made and relevant mathematical support to deal with response to binary mixtures has been provided $[3,69,70]$. However, despite the similarities between human and insect perceptions of odors, psychophysics' models cannot be applied here because behavioral responses and their quantification methods are very different.

In $R$. palmarum, mixing pheromone and kairomone synergized the walking responses of the animal at short distance for doses ranging over two orders of the magnitude. A significant mixture effect was recorded at a dose below the response thresholds for each component. Although a response threshold to pheromone-kairomone mixture still needs to be determined, the response threshold to plant odor appears to be considerably lowered by co-perception of a small amount of pheromone.
Therefore, for this specie, the male aggregation pheromone primarily optimizes host plant localization and does not carry sex information as supported by the absence of sexual dimorphism in the response. This is one of the evolutionary roles, possibly played by such pheromone in non-social insects [13]. The 'insect-plant' synergistic signal does not induce grouping in mass, and therefore, does not contribute to overcoming plant defenses as for aggressive bark beetles [6,71]. Synergy occurred for various ratios of pheromone and plant odor for which the lower the pheromone dose, the higher the synergy. In Carpophilus beetles, synergy between pheromone and plant volatile was demonstrated essentially for large excesses of kairomone (typically > 100:1); [37,72]. Similarly a large excess of plant volatiles with female sex pheromone synergized attraction of codling moth, Cydia pomonella, [73] and diamondback moth, Pluttella xylostella, [74] males. Varying the P: $\mathrm{K}$ ratio modified the responses of $C$. pomonella males, affecting either flight activation, or final localization of the odor source [73]. A large excess of one (1 to 
10 or more as evaluated in the choice configuration) or the other semiochemical in the mixture should be further evaluated in $R$. palmarum because the response thresholds to either information alone were close.

\section{Acknowledgements}

The work was supported by a European Union funding (INCO project ERBIC-18CT970199), and from the Ministry of Scientific Research, Technology and Competencies Development in Tunisia through funding of the research program contract (2004-2008) for Institut Pasteur de Tunis. We thank Bernard Perthuis (CIRAD-CP, Kourou, French Guyana), who sent us R. palmarum for behavioral tests, Robert J. Bartelt for helpful comments about an earlier version of the work, Jean-Pierre Rospars for help in modeling, Michel Renou for helpful discussions, Anne Porter Cloarec for English revision, and anonymous reviewers for very valuables comments.

\section{Author details}

'Unité de Biochimie Macromoléculaire et Génétique, Faculté des sciences de Gafsa, cité Zarroug, 2112 Gafsa, Université de Gafsa, Tunisia. ${ }^{2}$ Laboratory of Epidemiology and Ecology of Parasites, Institut Pasteur de Tunis, TunisBelvedère, 1002, Tunisia. ${ }^{3}$ UMR1272, Physiologie de I'Insecte: Signalisation et Communication, UPMC - INRA - AgroParisTech, R.D. 10, F-78026 Versailles cedex, France.

\section{Authors' contributions}

IS designed, and performed the experimentation. BK performed the statistical analysis, and the interpretation of the results. DR performed the mathematical modeling, supervised, and directed the study. All authors contributed significantly in the drafting of the manuscript. All authors have read and approved the manuscript.

\section{Competing interests}

The authors declare that they have no competing interests.

Received: 15 November 2010 Accepted: 4 April 2011

Published: 4 April 2011

\section{References}

1. Alonso-Amelot ME, Calcagno MP: Modeling synergistic and antagonistic interactions in xenobiotic compounds. J Chem Ecol 2000, 26:513-531.

2. Berenbaum MC: What is synergy? Pharmacol Rev 1989, 41:93-141.

3. Laffort P: Synergie et inhibition en olfaction. In Odeurs et désodorisation dans l'environnement. Edited by: Martin G, Laffort P. Paris: Tec and Doc Lavoisier; 1991:169-194.

4. Laing DG, Cain WS, McBride RL, Ache BW: Perception of complex smells and tastes Sydney, Australia: Academic Press; 1989.

5. Silverstein RM, Rodin JO, Wood DL: Methodology for isolation and identification of insect pheromones with reference to studies on California five-spined Ips. J Econ Entomol 1967, 60:944-949.

6. Landolt PJ, Phillips WT: Host plant influences on sex pheromone behavioral phytophagous insects. Annu Rev Entomol 1997, 42:371-391.

7. McKey D: The distribution of secondary compounds within plants. In Herbivores, their interaction with secondary plant metabolites. Edited by: Rosenthal GA, Janean DH. New York: Academic Press; 1979:55-133.

8. McNeil J, Delisle J: Are host plants important in pheromone-mediated mating systems of Lepidoptera? Experientia 1989, 45:236-240.

9. Visser JH: Host odour perception in phytophagous insects. Annu ReV Entomol 1986, 31:121-144.

10. Bartelt RJ: Sap beetles. In Pheromones of Non-Lepidopteran Insects Associated with Agricultural Plants. Edited by: Hardie J, Minks AK. Wallingford, UK: CABI Publishing; 1999:69-89.

11. Giblin-Davis RM, Oehlschlager AC, Perez A, Gries G, Gries R, Weissling TJ, Chinchilla CM, Pena JE, Hallett RH, Pierce HD, Gonzalez LM: Chemical and behavioral ecology of palm weevils (Curculionidae: Rhynchophorinae). Fla Entomol 1996, 79:153-167.

12. Wood DL: The role of pheromones, kairomones and allomones in the host selection and colonization behavior of bark beetles. Annu Rev Entomol 1982, 27:411-446.
13. Wertheim B, van Baalen EJA, Dicke M, Vet LEM: Pheromone-mediated aggregation in nonsocial arthropods: An evolutionary ecological perspective. Annu Rev Entomol 2005, 50:321-346.

14. Oehlschlager AC, Chinchilla CM, Gonzalez LM, Jiron LF, Mexzon R, Morgan B: Development of a pheromone-based trapping system for Rhynchophorus palmarum (Coleoptera: Curculionidae). J Econ Entomol 1993, 86:1381-1392.

15. Rochat D, Gonzalez AV, Mariau D, Villanueva AG, Zagatti P: Evidence for male-produced aggregation pheromone in American palm weevil, Rhynchophorus palmarum (L.) (Coleoptera: Curculionidae). J Chem Ecol 1991, 17:1221-1230.

16. Ferreira JMS, Leal MdLdS, Sarro FB, Araujo RPC, Moura JIL: Avaliação de diferentes fontes atrativas e suas prováveis interações na captura de Rhynchophorus palmarum. Manejo Integrado de Plagas y Agroecologia (Costa Rica) 2003, 67:23-29.

17. Said I, Renou M, Morin JP, Ferreira JMS, Rochat D: Interactions between acetoin, a plant volatile, and pheromone in Rhynchophorus palmarum: Behavioral and olfactory neuron responses. J Chem Ecol 2005, 31:1789-1805.

18. El-Sayed AM, Suckling DM, Wearing CH, Byers JA: Potential of mass trapping for long-term pest management and eradication of invasive species. J Econ Entomol 2006, 99:1550-1564.

19. Faleiro JR, Abraham VA, Nabil N, Al-Shuaibi MA, Kumar TP: Field evaluation of red palm weevil, Rhynchophorus ferrugineus Oliv. pheromone (Ferrugineol) lures. Indian J Entomol 2000, 62:427-433.

20. Faleiro JR, Satarkar VR: Ferrugineol based pheromone lures for trapping Red Palm Weevil, Rhynchophorus ferrugineus Olivier (Coleoptera: Rhynchophoridae) in coconut plantations. Indian J Plant Prot 2003, 31:84-87.

21. Giblin-Davis RM, Gries R, Gries G, PenaRojas E, Pinzon I, Pena JE, Perez AL, Pierce HD, Oehlschlager AC: Aggregation pheromone of palm weevil, Dynamis borassi. J Chem Ecol 1997, 23:2287-2297.

22. Hallett RH, Oehlschlager AC, Borden JH: Pheromone trapping protocols for the Asian palm weevil, Rhynchophorus ferrugineus (Coleoptera : Curculionidae). Int J Pest Manag 1999, 45:231-237.

23. Oehlschlager AC, McDonald RS, Chinchilla CM, Patschke SN: Influence of a pheromone-based mass-trapping system on the distribution of Rhynchophorus palmarum (Coleoptera: Curculionidae) in oil palm. Environ Entomol 1995, 24:1005-1012.

24. Oehlschlager AC, Chinchilla C, Castillo G, Gonzalez L: Control of red ring disease by mass trapping of Rhynchophorus palmarum (Coleoptera : Curculionidae). Fla Entomol 2002, 85:507-513.

25. Oehlschlager AC, Gonzalez L, Gomez M, Rodriguez C, Andrade R: Pheromone-based trapping of West Indian sugarcane weevil in a sugarcane plantation. J Chem Ecol 2002, 28:1653-1664

26. Perez AL, Campos Y, Chinchilla CM, Oehlschlager AC, Gries G, Gries R, Giblin-Davis RM, Castrillo G, Peña JE, Duncan RE, Gonzalez LM, Pierce HD Jr, McDonald R, Andrade R: Aggregation pheromones and host kairomones of West Indian sugarcane weevil, Metamasius hemipterus sericeus. J Chem Ecol 1997, 23:869-888.

27. Rochat D, Nagnan-Le Meillour P, Esteban-Duran JR, Malosse C, Perthuis B, Morin JP, Descoins C: Identification of pheromone synergists in American palm weevil, Rhynchophorus palmarum, and attraction of related Dynamis borassi. J Chem Ecol 2000, 26:155-187.

28. Witzgall P, Kirsch P, Cork A: Sex Pheromones and Their Impact on Pest Management. J Chem Ecol 2010, 36:80-100.

29. Abraham VA, Faleiro JR, Al-Shuaibi MA, Prem Kumar T: A strategy to manage red palm weevil Rhynchophorus ferrugineus Oliv. on date palm Phoenix dactylifera L. Its successful implementation in Al-Hassa, Kingdom of Saudi Arabia. Pestology 2000, 24:23-30.

30. Giblin-Davis RM, Weissling TJ, Oehlschlager AC, Gonzalez LM: Field response of Rhynchophorus cruentatus (Coleoptera: Curculionidae) to its aggregation pheromone and fermenting plant volatiles. Fla Entomol 1994, 77:164-177.

31. Giblin-Davis RM, Peña JE, Oehlschlager AC, Perez AL: Optimization of semiochemical-based trapping of Metamasius hemipterus sericeus (Olivier) (Coleoptera: Curculionidae). J Chem Ecol 1996, 22:1389-1410

32. Gries G, Gries R, Perez AL, Gonzales LM, Pierce HD, Oehlschlager AC, Rhainds M, Zebeyou M, Kouame B: Ethyl propionate: synergistic kairomone for african palm weevil, Rhynchophorus phoenicis $\mathrm{L}$. (Coleoptera: Curculionidae). J Chem Ecol 1994, 20:889-897. 
33. Gunawardena NE, Kern F, Janssen E, Meegoda C, Schafer D, Vostrowsky O, Bestmann HJ: Host attractants for red weevil, Rhynchophorus ferrugineus: Identification, electrophysiological activity, and laboratory bioassay. $J$ Chem Ecol 1998, 24:425-437.

34. Jaffé K, Sánchez P, Cerda H, Hernández JV, Jaffé R, Urdaneta N, Guerra G, Martínez R, Miras B: Chemical ecology of the palm weevil Rhynchophorus palmarum (L) (Coleoptera: Curculionidae): attraction to host plants and to a male-produced aggregation pheromone. J Chem Ecol 1993, 19:1703-1720.

35. Oehlschlager AC, Pierce HD Jr, Morgan B, Wimalaratne PDC, Slessor KN, King GGS, Gries G, Gries R, Borden JH, Jiron LF, Chinchilla CM, Mexzan RG: Chirality and field activity of rhynchophorol, the aggregation pheromone of the American palm weevil. Naturwissenschaften 1992, 79:134-135.

36. El-Sebay Y: Ecological studies on the red palm weevil Rhynchophorus ferrugineus Oliv., (Coleoptera : Curculionidae) in Egypt. Egyptian J Agric Res 2003, 81:523-529.

37. Dowd PF, Bartelt RJ: Host-derived volatiles as attractants and pheromone synergists for driedfruit beetle, Carpophilus hemipterus. J Chem Ecol 1991, 17:285-308.

38. Gunawardena NE, Herath HMWKB: Enhancement of the activity of ferrugineol by $\mathrm{N}$-pentanol in an attractant baited trap for the coconut pest, Rhynchophorus ferrugineus F. (Coleoptera: Curculionidae). I Nat/ SCl Council Sri Lanka 1995, 23:81-86.

39. Vet LEM, Van Lenteren JC, Heymans M, Meelis E: An airflow olfactometer for measuring olfactory responses of Hymenopterous parasitoids and other small insects. Physiol Entomol 1983, 8:97-106.

40. Bartelt RJ, Zilkowski BW: A versatile and quantitative volatile-delivery system for laboratory bioassays. J Chem Ecol 1998, 24:183-187.

41. Said I, de la Torre RA, Morin JP, Rochat D: Adaptation of a four-arm olfactometer for behavioural bioassays of large beetles. Chemoecology 2006, 16:9-16

42. Rochat $D$, Malosse $C$, Lettere $M$, Ducrot PH, Zagatti $P$, Renou M, Descoins C: Male-produced aggregation pheromone of the American palm weevil, Rhynchophorus palmarum (L.) (Coleoptera: Curculionidae): collection, identification, electrophysiological activity, and loboratory bioassay. $J$ Chem Ecol 1991, 17:2127-2141.

43. Siegel S: Non parametric statistics for the behavioral sciences New York: McGraw Hill Book Company; 1956.

44. Dagnelie P: Théorie et méthodes statistiques, applications agronomiques Belgium: Les presses agronomiques de Gembloux; 1975.

45. Loewe S: The problem of synergism and antagonism of combined drugs. Arzneimittelforschung 1953, 3:285-290.

46. Loewe S: Antagonism and antagonists. Pharmacol Rev 1957, 9:237-242.

47. Tallarida RJ: Drug Synergism and Dose-Effect Data Analysis Boca Raton: Chapman Hall/CRC Press; 2000.

48. Matlab. City: Math Works Inc; 2002, version 6.5

49. Office Excel. Microsoft Corp; 1985, version 10.

50. Debouche C: Présentation coordonnées de différents modèles de croissance. Rev Stat Appl [Fr] 1979, 27:5-22.

51. Baker TC, Cardé RT: Techniques for behavioral bioassays. In Techniques in pheromone research. Edited by: Hummel HE, Miller TA. Springer-Verlag inc., New York; 1984:45-73.

52. Baker TC, Linn CE Jr: Wind tunnels in pheromone research. In Techniques in pheromone research. Edited by: Hummel HE, Miller TA. Springer-Verlag inc., New York; 1984:75-110.

53. Iwabuchi K, Takahashi J, Nakagawa Y, Sakai T: Behavioral responses of female grape borer Xylotrechus pyrrhoderus Bates (Coleoptera: Cerambycidae) to synthetic male sex pheromone components. Appl Entomol Zool 1986, 21:21-27.

54. Sakai M, Yamasaki T: (+)-juniperol and (+)-pimaral: attractants for the cerambycid beetle, Monochamus alternatus Hope. J Chem Ecol 1990, 16:3383-3392.

55. Renwick JAA, Chew FS: Oviposition behavior in Lepidoptera. Annu Rev Entomol 1994, 39:377-400.

56. Rochat D, Ramirez-Lucas P, Malosse C, Aldana R, Kakul T, Morin JP: Role of solid-phase microextraction in the identification of highly volatile pheromones of two rhinoceros beetles Scapanes australis and Strategus aloeus (Coleoptera: Scarabaeidae; Dynastinae). J Chromatogr A 2000, 885:433-444.

57. Byers JA: Chemical ecology of bark beetles. Experientia 1989, 45:271-283.
58. Byers JA: Host-tree chemistry affecting colonization in bark beetles. In Chemical ecology of insects. Volume 2. Edited by: Cardé RT, Bell WJ. Chapman and Hall, New York; 1995:154-213.

59. Byers JA: Chemical ecology of bark beetles in a complex olfactory landscape. In Bark and Wood Boring Insects in Living Trees in Europe, a Synthesis. Edited by: Lieutier F, Day KR, Battisti A, Grégoire JC, Evans H. Dordrecht, The Netherlands: Kluwer Academic Publishers; 2004:89-134.

60. Saïd I, Tauban D, Renou M, Mori K, Rochat D: Structure and function of the antennal sensilla of the palm weevil Rhynchophorus palmarum (Coleoptera, Curculionidae). J Insect Physiol 2003, 49:857-872.

61. de Bruyne M, Foster K, Carlson JR: Odor coding in the Drosophila antenna. Neuron 2001, 30:537-552

62. Stensmyr MC, Dekker T, Hansson BS: Evolution of the olfactory code in the Drosophila melanogaster subgroup. Proc R Soc London B 2003, 270:2333-2340.

63. Stensmyr MC, Giordano E, Balloi A, Angioy AM, Hansson BS: Novel natural ligands for Drosophila olfactory receptor neurones. J Exp Biol 2003, 206:715-724.

64. Bartelt RJ, Carlson DG, Vetter RS, Baker TC: Male-produced aggregation pheromone of Carpophilus mutilatus (Coleoptera: Nitidulidae). J Chem Ecol 1993, 19:107-118.

65. Bartelt RJ, James DG: Aggregation pheromone of australian sap beetle, Carpophilus davidsoni (Coleoptera: nitidulidae). J Chem Ecol 1994, 20:3207-3219.

66. James DG, Bartelt RJ, Moore CJ: Mass-trapping of Carpophilus spp. (Coleoptera: Nitidulidae) in stone fruit orchards using synthetic aggregation pheromones and a coattractant: development of a strategy for population suppression. J Chem Ecol 1996, 22:1541-1556.

67. Lin H, Phelan PL: Identification of food volatiles attractive to dusky sap beetle, Carpophilus lugubris (Coleoptera: Nitidulidae). J Chem Ecol 1991, 17:1273-1286.

68. Phelan PL, Lin H: Chemical characterization of fruit and fungal volatiles attractive to dried-fruit beetle, Carpophilus hemipterus (L.) (Coleoptera: Nitidulidae). J Chem Ecol 1991, 17:1253-1272.

69. Berglund $B$, Berglund $U$, Lindvall $T$, Svensson $L T$ : A quantitative principle of perceived intensity summation in odor mixtures. J Exp Psychol 1973, 100:29-38.

70. Laffort $P$, Walsh RM, Spillane WJ: Application of the $U$ and Gamma' models in binary sweet taste mixtures. Chem Senses 2002, 27:511-520.

71. Borden $\mathrm{JH}$ : Aggregation pheromones. In Comprehensive insect physiology, biochemistry, and pharmacology. Volume 9. Edited by: Kerkut GA, Gilbert LI. Pergamon Press, Oxford; 1985:257-285.

72. Zilkowski BW, Bartelt RJ, Blumberg D, James DG, Weaver DK: Identification of host-related volatile attractive to pineapple beetle Carpophilus humeralis. J Chem Ecol 1999, 25:225-259.

73. Yang $Z \mathrm{H}$, Bengtsson $M$, Witzgall P: Host plant volatiles synergize response to sex pheromone in codling moth, Cydia pomonella. J Chem Ecol 2004, 30:619-629.

74. Reddy GVP, Guerrero A: Behavioral responses of the diamondback moth, Plutella xylostella, to green leaf volatiles of Brassica oleracea subsp capitata. J Agric Food Chem 2000, 48:6025-6029.

doi:10.1186/1752-153X-5-14

Cite this article as: Saïd et al.: Evaluation and modeling of synergy to pheromone and plant kairomone in American palm weevil. Chemistry Central Journal 2011 5:14. 